\title{
Reflex Vascular Responses to Left Ventricular Outflow Obstruction and Activation of
}

\section{Ventricular Baroreceptors in Dogs}

\author{
Allyn L. Mark, Francois M. Abboud, Phillip G. Schmid, \\ and Donald D. Heistad with the technical assistance of \\ U. JAMES JOHANNSEN \\ From the Cardiovascular Division, Department of Internal Medicine, \\ University of Iowa College of Medicine and the Veterans Administration \\ Hospital, Iowa City, Iowa 52240
}

A B S T R A C T Reflex vascular responses to acute left ventricular outflow obstruction were studied in anesthetized dogs. The studies were done to compare the effects of activation of ventricular baroreceptors on vascular resistance in skeletal muscle (gracilis muscle) and skin (hindpaw); to identify afferent and efferent pathways which mediate the reflex vasodilatation; and to assess the relative contribution of ventricular baroreceptors and baroreceptors in left atrium and pulmonary vessels in responses to left ventricular outflow obstruction. The gracilis artery and the cranial tibial artery to the paw were perfused separately at constant flow. Changes in perfusion pressure to each bed reflected changes in vascular resistance. Outflow obstruction was produced by inflating a balloon in the left ventricular outflow tract for $15 \mathrm{~s}$ while pressures in the left ventricle and aortic arch were measured.

Inflation of the balloon increased left ventricular pressure and decreased pressure in the aortic arch. Low and high levels of obstruction produced dilator responses averaging $-5 \pm 3(\mathrm{SE})$ and $-42 \pm 11 \mathrm{~mm} \mathrm{Hg}$ in muscle and $-1 \pm 1$ and $-3 \pm 2 \mathrm{~mm} \mathrm{Hg}$ in paw. Denervation, phentolamine, and glyceryltrinitrate caused greater dilatation in paw than did left ventricular outflow obstruction. This indicates that dilator responses in the paw were not limited by a low level of resting neurogenic constrictor tone or by a negligible dilator capacity of these vessels.

This work was presented in part at the 44th Annual Scientific Sessions of the American Heart Association, Anaheim, California, 12 November 1971.

A preliminary report has appeared in abstract form, Circulation. 43: II-76.

Received for publication 2 November 1972 and in revised form 15 January 1973.
Obstruction to left ventricular inflow increased left atrial pressure, but did not cause reflex vasodilatation. This suggests that low pressure baroreceptors in atria or pulmonary vessels did not contribute to vasodilator responses to left ventricular outflow obstruction.

Vasodilator responses to outflow obstruction were blocked by bilateral vagotomy, sectioning the sciatic and obturator nerves, and administration of phentolamine, but were not decreased by atropine or tripelennamine.

The results indicate that activation of left ventricular baroreceptors produces striking vasodilatation in skeletal muscle, but only slight vasodilatation in skin. The data suggest that the difference in dilator responses in the two beds results from greater withdrawal of adrenergic constrictor tone to skeletal muscle than to skin. Activation of sympathetic cholinergic or histaminergic dilator pathways does not contribute to the dilatation.

\section{INTRODUCTION}

Left ventricular distention in dogs produces reflex hypotension and vasodilatation (1-3).

In the preceding study, we demonstrated that reflex forearm vasoconstrictor responses to leg exercise are reversed in patients with aortic stenosis and a history of syncope. We suggested that this reversal results from increases in left ventricular stretch and activation of ventricular baroreceptors (4).

The present experiments in dogs were done to explore further the mechanism by which left ventricular outflow obstruction might promote vasodilatation.

We assessed the relative contribution of ventricular baroreceptors and of low pressure baroreceptors in atria 
and pulmonary vessels to the reflex vasodilator response to left ventricular outflow obstruction. These experiments were done because left atrial pressure, as well as left ventricular pressure, increases during outflow obstruction.

Since some reflex stimuli produce different effects on vessels in skin and skeletal muscle (5-6), we compared effects of left ventricular outflow obstruction on vascular resistance in the gracilis muscle and in the hindpaw, which has a predominantly cutaneous vascular bed.

Studies also were performed to identify the efferent components of the sympathetic nervous system which are involved in reflex vasodilaattion during left ventricular outflow obstruction. We wanted to determine if the vasodilatation results from withdrawal of adrenergic constrictor tone or from activation of sympathetic cholinergic or histaminergic dilator pathways (7-9).

Specifically, the experiments were designed: $(a)$ to compare effects of left ventricular outflow obstruction on vascular resistance in skeletal muscle and skin, (b) to define the mechanism for differences in responses in the two beds, $(c)$ to assess the relative role of ventricular baroreceptors and of left atrial or pulmonary vascular baroreceptors in responses to left ventricular outflow obstruction, $(d)$ to identify afferent and efferent pathways, particularly the efferent component of the sympathetic nervous system which is involved in the dilatation, and $(e)$ to determine if an intact carotid sinus reflex attenuates the dilator responses to left ventricular outflow obstruction and activation of ventricular baroreceptors.

\section{METHODS}

Male mongrel dogs weighing 22-29 $\mathrm{kg}$ were anesthetized with chloralose, $50 \mathrm{mg} / \mathrm{kg}$, and urethane, 500 $\mathrm{mg} / \mathrm{kg}$, treated with decamethonium bromide, 0.3 $\mathrm{mg} / \mathrm{kg}$, intravenous (i.v.), and ventilated artificially.

The cranial tibial artery to the hindpaw was exposed near the tarsus, and collateral arteries at this level were ligated. The gracilis muscle in the same limb was dissected free from surrounding tissues with the exception of the gracilis artery, vein, and nerve. The cranial tibial and gracilis arteries were cannulated and perfused separately at constant flow with heparinized arterial blood from a femoral artery and a small reservoir while perfusion pressures were recorded. Flows ranged from $18-22 \mathrm{ml} / \mathrm{min}$ to the hindpaw and $8-12 \mathrm{ml} / \mathrm{min}$ to the muscle; these flows produced perfusion pressures in the same range as arterial pressure at the start of the study. With flow constant, changes in perfusion pressure to each bed indicated changes in vascular resistance. Perfusion pressures abruptly fell to $10-20 \mathrm{~mm} \mathrm{Hg}$ when the pumps were stopped, and there was little or no back flow of blood from the distal end of the partially transected vessels suggesting that there was little or no collateral flow. Perfusion pressures did not fall when the inflow tubing to the reservoir was clamped for $90 \mathrm{~s}$. This observation indicates that during the interventions flows and perfusion pressures were independent of changes in arterial pressure.

A rigid double lumen balloon cannula was inserted into the left carotid artery and advanced so that the tip was in the outflow tract of the left ventricle. Pressure at the tip of this cannula was measured. A balloon located $5 \mathrm{~mm}$ from the tip of the cannula was inflated with $5-20 \mathrm{ml}$ of air to produce left ventricular outflow obstruction. Arterial pressure was measured with a catheter in the aortic arch. The position of the catheter in the aortic arch was determined either by palpating the tip through a thoractomy or by inserting the tip into the left ventricle and withdrawing the catheter 1-2 $\mathrm{cm}$ beyond the point where the pressure contour changed from vnetricular to arterial. Inflation of the balloon increased left ventricular pressure and decreased in the aortic arch.

We measured responses to two levels of left ventricular outflow obstruction in muscle and paw in six dogs. The low level of obstruction was produced by rapidly inflating the balloon with $7.5-10.0 \mathrm{ml}$ of air for $15 \mathrm{~s}$. The high level was produced by inflating with 15.0 $20.0 \mathrm{ml}$.

In 11 experiments, we compared dilator responses in paw during ventricular outflow obstruction with dilator responses caused by denervation $(n=5)$, phentolamine (2.5 mg intraarterial (i.a.); $n=4$ ) and glyceryltrinitrate $(6 \mu$ g i.a. $;=10)$. These comparisons were made to determine if dilatation in the paw during outflow obstruction was limited either by a low level of adrenergic constrictor tone or by the dilator capacity of vessels in the paw.

The relative contribution of left ventricular baroreceptors and low pressure baroreceptors in the left atrium or pulmonary vessels was studied in four experiments by comparing responses to left ventricular outflow and inflow obstruction. Inflow obstruction was produced by inserting a flexible balloon catheter in to the left atrium and inflating the balloon at the mitral valve to increase left atrial pressure. Decreases in arterial pressure, which promote reflex vasoconstriction by activating carotid sinus reflexes, were greater during outflow than inflow obstruction. In order to minimize effects of the difference in the arterial pressure response on the comparison of the vascular responses to outflow and inflow obstruction, the carotid sinuses were denervated before these interventions.

Responses to outflow obstruction were obtained before and after bilateral cervical vagotomy in three experiments, and before and after cutting the obturator and sciatic nerves to muscle and paw, respectively, in three experiments. These experiments were done to 
demonstrate that the responses were neurogenically mediated and to identify afferent and efferent pathways.

We then performed experiments to identify the efferent component of the sympathetic nervous system which mediated the vasodilatation. In four studies responses to outflow obstruction were obtained before and after administration of the alpha receptor blocking agent, phentolamine ( $2.5 \mathrm{mg}$ i.a.), which was given to release adrenergic constrictor tone. Phenylephrine (4 $\mu$ g i.a.) was injected to test effectiveness of blockade by phentolamine. The rationale of the experiments with phentolamine was that if the dilator response to outflow obstruction results from withdrawal of adrenergic constrictor tone, then release of resting adrenergic constrictor tone with phentolamine would prevent the dilatation. As a result of previous experiments with phentolamine, we anticipated a problem in the interpretation of these experiments since phentolamine not only reduces dilator responses which result from withdrawal of adrenergic constrictor tone, but also reduces responsiveness to other dilator stimuli (for example, glyceryltrinitrate) by decreasing resting vascular resistance. This raised the possibility that phentolamine might block the dilator responses to outflow obstruction specifically by preventing withdrawal of adrenergic constrictor tone or nonspecifically by reducing the dilator capacity of these vessels. In order to determine if phentolamine was blocking the dilatation specifically by preventing withdrawal of adrenergic constrictor tone, we used the ratio of the dilator response to outflow obstruction divided by the dilator response to the nonspecific vasodilator, glyceryltrinitrate. A decrease in the ratio after phentolamine would indicate a specific blockade of the dilatation during outflow obstruction. Responses also were measured before and after administration of atropine (1.0 $\mathrm{mg}$ i.v.) and tripelennamine (5.0 $\mathrm{mg}$ i.v.), which were given to determine if the dilatation resulted from activation of sympathetic cholinergic or histaminergic dilator pathways. Efficacy and specificity of blockade with these agents were tested with injections of acetylcholine (16 $\mu \mathrm{g}$ i.a.), histamine (2 $\mu \mathrm{g}$ i.a.), and glyceryltrinitrate (6 $\mu \mathrm{g}$ i.a.).

In four additional experiments, we obtained responses to outflow obstruction and to carotid occlusion before and after cutting the carotid sinus nerves. These experiments were done to see if abolishing the carotid sinus reflex augments dilator responses to outflow obstruction by preventing reflex vasoconstrictor responses to decreases in arterial pressure.

Statistical comparisons were performed with the $t$ test for paired data (10). Statistical significance was indicated by $P$ values $<0.05$. The one-tailed $t$ test was used to analyze effects of vagotomy, denervation, and blocking drugs on vasodilator responses.

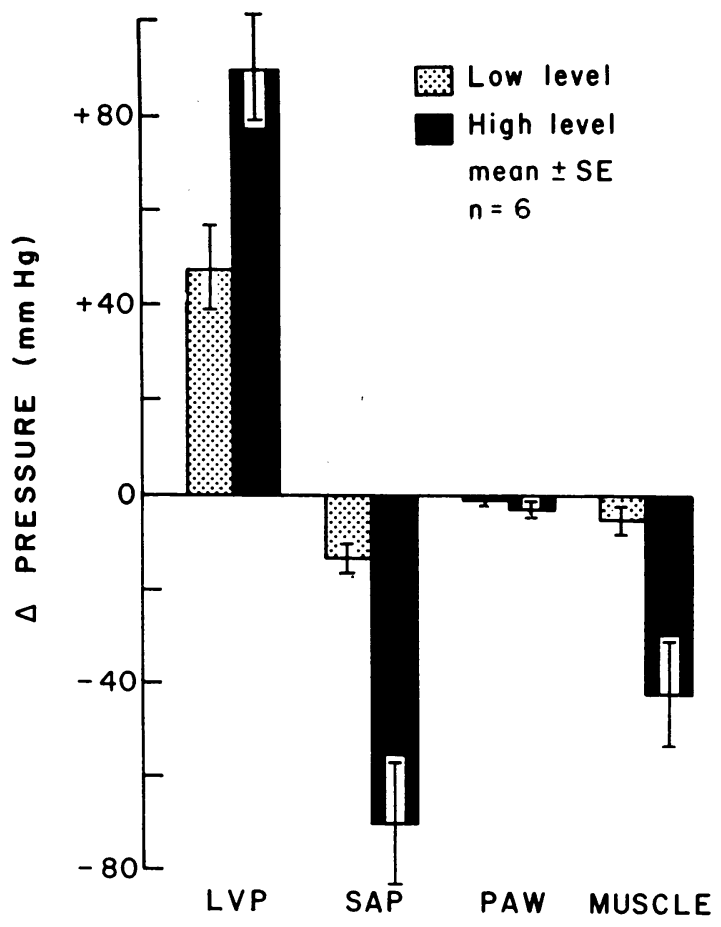

Ficitre 1 Responses to two levels of left ventricular outflow obstruction. LVP, left ventricular pressure, SAP, systemic arterial pressure measured in the aortic arch; PAW, perfusion pressure to hindpaw; and MUSCLE, perfusion pressure to gracilis muscle.

\section{RESULTS}

Responses to graded left ventricular outflow obstruction. Inflation of the balloon in the left ventricular outflow tract increased $(P<0.05)$ left ventricular pressure and decreased $(P<0.05)$ pressure in the aortic arch (Figs. 1 and 2). Increases in left ventricular pressure were associated with pronounced vasodilatation in muscle and slight, insignificant vasodilatation in paw (Fig. 1).

Vasodilator responses to outflow obstruction in the paw were compared with vasodilator responses to denervation, phentolamine, and glyceryltrinitrate in another group of experiments. In these experiments, decreases in perfusion pressure in paw with outflow obstruction averaged $-11 \pm 3(\mathrm{SE}) \mathrm{mm} \mathrm{Hg}$ and were significantly less $(P<0.05)$ than decreases with denervation $(-46 \pm 10 \mathrm{~mm} \mathrm{Hg})$, phentolamine $(-70 \pm 25 \mathrm{~mm} \mathrm{Hg})$, and glyceryltrinitrate $(-33 \pm 6 \mathrm{~mm} \mathrm{Hg})$.

Comparison of vascular responses to left ventricular outflow and inflow obstruction. Outflow obstruction increased $(P<0.05)$ left ventricular and left atrial pressures and produced significant vasodilatation (Figs. 2 and 3 ). In contrast, inflow obstruction, which resulted in increases in left atrial pressure comparable to those with outflow obstruction, failed to produce vasodilatation (Figs. 2 and 3). 


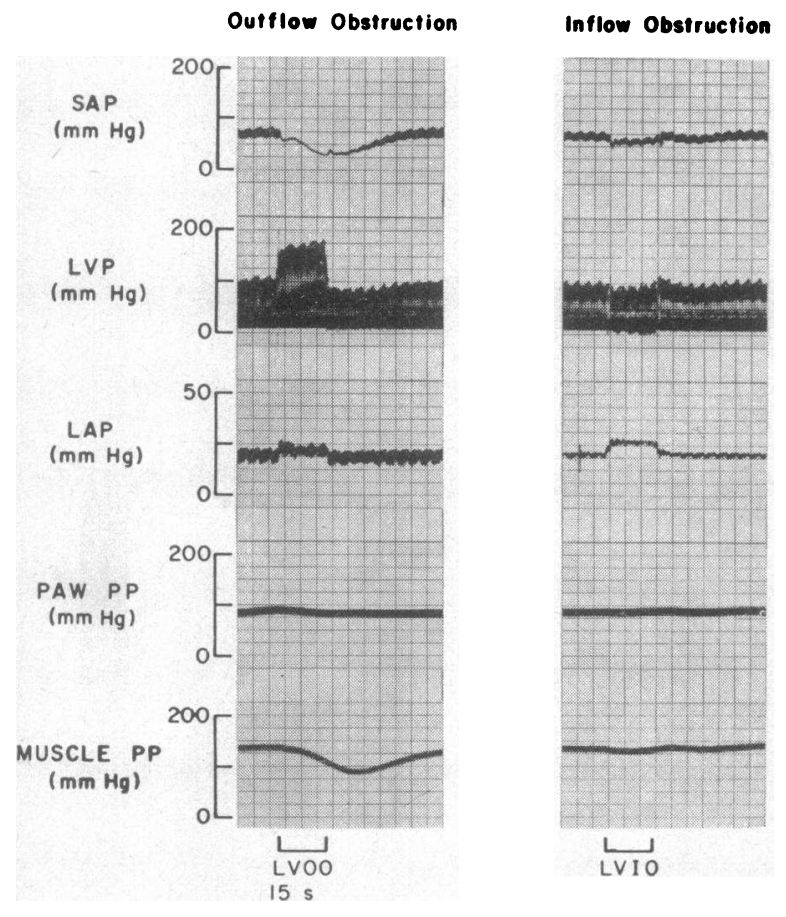

FigURE 2 Comparison of left ventricular outflow (LVOO) and inflow (LVIO) obstruction.

Effects of vagotomy and denervation. Vasodilator responses in paw and muscle were blocked $(P<0.05)$ by vagotomy or by cutting the sciatic and obturator

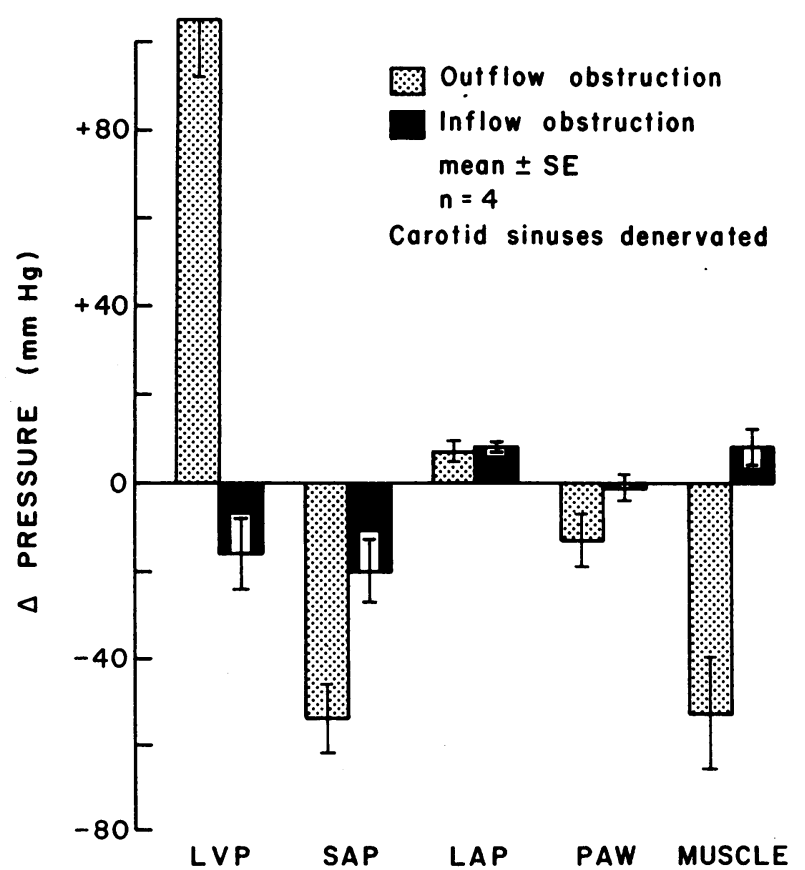

Figure 3 Responses to left ventricular outflow and inflow obstruction.

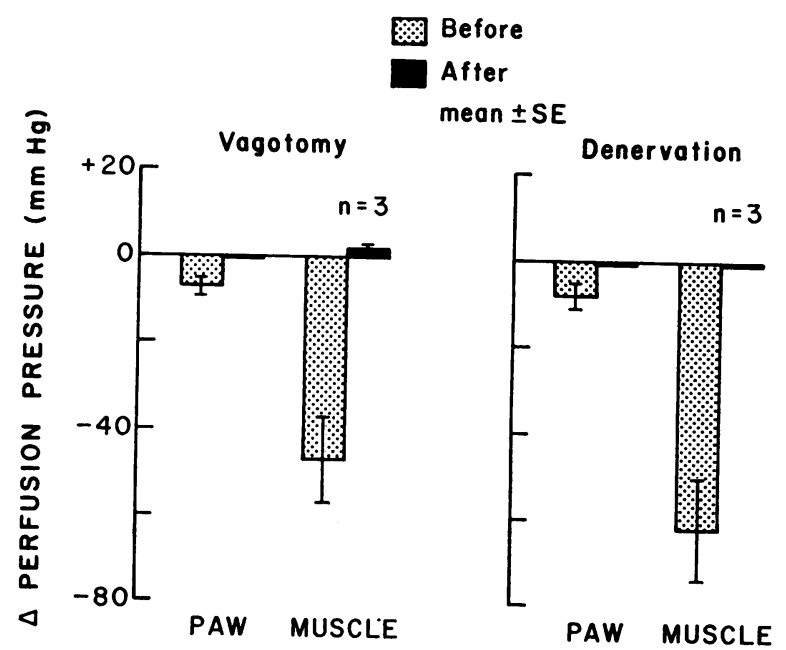

FIGURE 4 Effects of bilateral cervical vagotomy and of denervation of paw and muscle on vascular responses to left ventricular outflow obstruction.

nerves (Fig. 4). Increases in left ventricular pressure during outflow obstruction were similar $(P>0.05)$ before and after these interventions.

Effects of blocking agents. Phentolamine blocked $(P<0.05)$ dilator responses to outflow obstruction in paw and muscle (Fig. 5). This dose of phentolamine reduced vasoconstrictor responses to the alpha receptor stimulating agent, phenylephrine, from $103 \pm 33$ (mean $\pm \mathrm{SE}) \mathrm{mm} \mathrm{Hg}$ to $2 \pm 2 \mathrm{~mm} \mathrm{Hg}$ in paw $(P<0.05)$ and $17 \pm 4$ to $2 \pm 2 \mathrm{~mm} \mathrm{Hg}$ in muscle $(P<0.05)$. Phentolamine also reduced responses to glyceryltrinitrate, which was used as an internal dilator control, from $-40 \pm 7$ to $-7 \pm 2 \mathrm{~mm} \mathrm{Hg}$ in paw and $-38 \pm 7$ to $-18 \pm 4 \mathrm{~mm} \mathrm{Hg}$ in muscle $(P<0.05)$. This indicated that phentolamine reduced the dilator capacity of vessels in paw and muscle. In order to determine if the blockade of dilator responses to outflow obstruction with phentolamine resulted from specific or nonspecific effects, we used the ratio of dilator responses to outflow obstruction divided by dilator responses to an internal dilator control, glyceryltrinitrate. In three studies in muscle, the ratio was $3.40,0.88$, and 1.40 before phentolamine and $0.00,0.25$, and 0.20 after phentolamine, respectively. The decrease in the ratio after phentolamine indicates that the drug produced specific blockade of the dilator responses to outflow obstruction in addition to a reduction in the dilator capacity.

Atropine blocked $(P<0.05)$ dilator responses to acetylcholine, but did not decrease $(P>0.05)$ responses to outflow obstruction (Figs. 5 and 6). Responses to acetylcholine in paw and muscle averaged $-28 \pm 3$ and $-41 \pm 9 \mathrm{~mm} \mathrm{Hg}$ before and $-1 \pm 1$ and $-1 \pm 1 \mathrm{~mm} \mathrm{Hg}$ after atropine $(P<0.05)$. Administration of atropine did not alter dilator responses to 


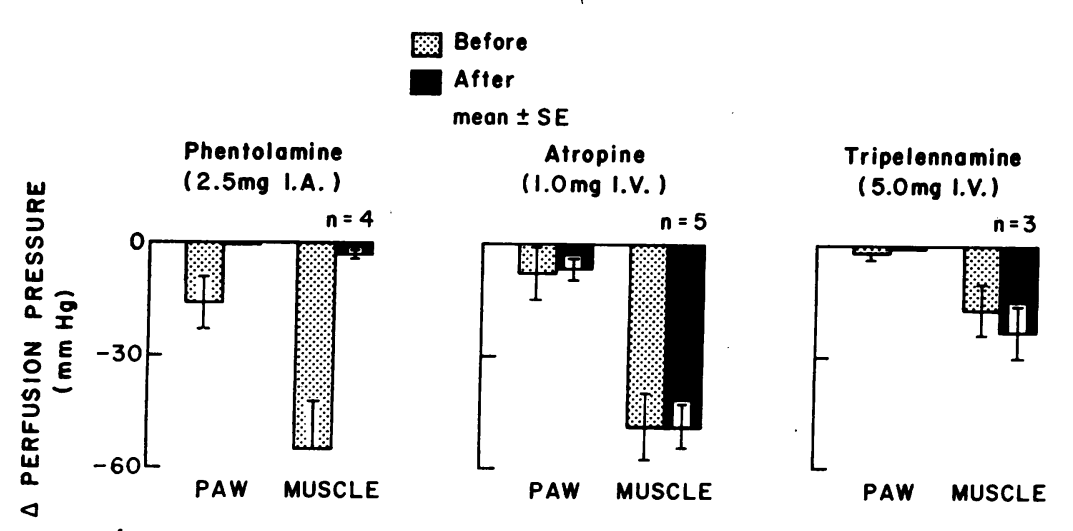

FIGURE 5 Effects of phentolamine, atropine and tripelennamine on responses to left ventricular outflow obstruction.

glycerltrinitrate; responses to glyceryltrinitrate in paw and muscle averaged $-28 \pm 3$ and $-45 \pm 2 \mathrm{~mm} \mathrm{Hg}$, respectively, before atropine and $-24 \pm 2$ and $-36 \pm 8$ $\mathrm{mm} \mathrm{Hg}$ after atropine $(P>0.05)$. Tripelennamine reduced dilator responses to histamine, but did not reduce $(P>0.05)$ dilator responses to outflow obstruction. Responses to histamine in paw and muscle averaged $-10 \pm 3$ and $-24 \pm 9 \mathrm{~mm} \mathrm{Hg}$, respectively, before tripelemennamine and $-2 \pm 2$ and $-3 \pm 2 \mathrm{~mm} \mathrm{Hg}$ after tripelennamine $(P<0.05)$. Dilator responses to glyceryltrinitrate in paw and muscle were not reduced and averaged $-18 \pm 6$ and $-27 \pm 7 \mathrm{~mm} \mathrm{Hg}$ before and $-27 \pm 4$ and $-43 \pm 4 \mathrm{~mm} \mathrm{Hg}$ after tripelennamine $(P>0.05)$.
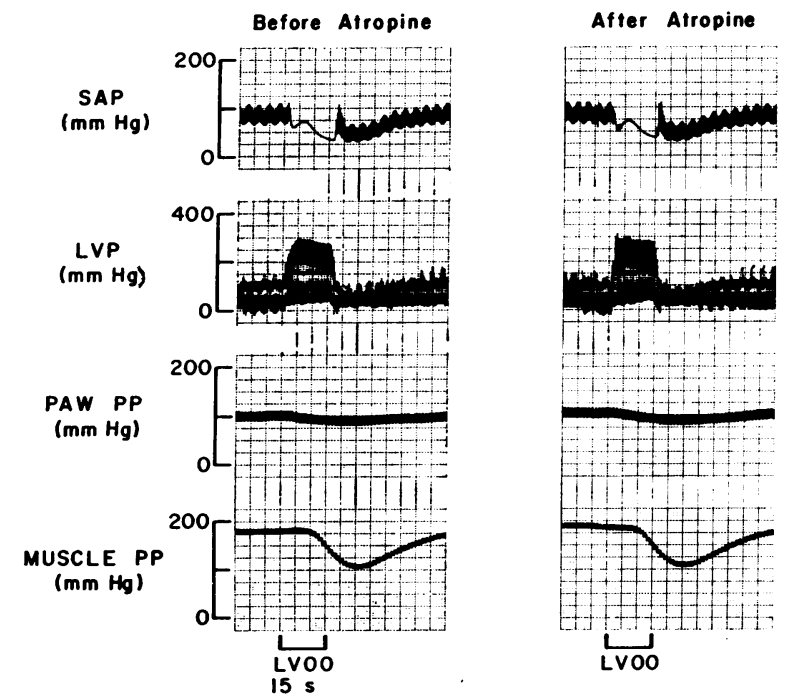

FIGURE 6 Responses to left ventricular outflow obstruction (LVOO) before and after atropine. The delay in the onset of the reflex vasodilator response in the muscle compared to skin was not a consistent finding.
E.ffects of carotid sinus denervation. Sectioning the carotid sinus nerves reduced $(P<0.05)$ vasoconstrictor and vasopressor responses to carotid occulsion (Fig. 7) and tended to augment vasodilator responses to outflow obstruction in muscle, but not in paw (Fig. 7). The vasodilator responses in the muscle were greater after carotid sinus denervation in each of the four dogs, and averaged $-25 \pm 9 \mathrm{~mm} \mathrm{Hg}$ before and $-56 \pm 22$ $\mathrm{mm} \mathrm{Hg}$ after carotid sinus denervation $(P>0.05)$. Increases in left ventricular pressure with outflow obstruction were less after denervation averaging $109 \pm 14$ before and $90 \pm 12 \mathrm{~mm} \mathrm{Hg}$ after denervation (Fig. 7).

\section{DISCUSSION}

These studies indicate that reflex vasodilatation in the extremities caused by left ventricular outflow obstruc-

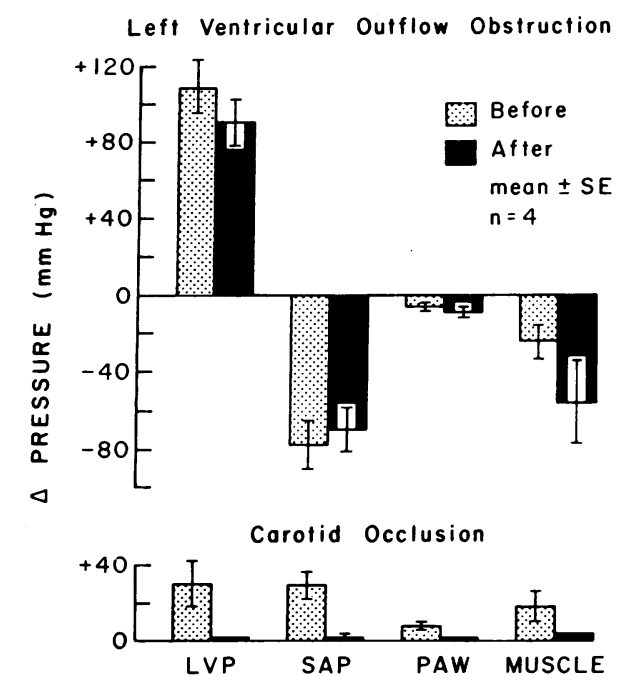

FIgURE 7 Responses of left ventricular outflow obstruction (top) and carotid occlusion (bottom) before and af ter denervation of carotid sinus. 
tion and activation of ventricular baroreceptors occurs predominately in skeletal muscle. Vasodilatation in the paw, which has a predominately cutaneous vascular bed, is minimal. We considered the possibility that the dilator response in the paw was limited either by a low level of resting neurogenic constrictor tone of cutaneous vessels or by a negligible dilator capacity of these vessels. These possibilities seem unlikely since denervation to release neurogenic tone, phentolamine to release adrenergic constrictor tone, and glyceryltrinitrate to test the dilator capacity of these vessels, all produced dilator responses which were greater than responses to left ventricular outflow obstruction. The earlier observation that another reflex stimulus, activation of arterial chemoreceptors, produces reflex vasodilatation in the paw (5) provides additional evidence that the dilator response in the paw was not limited by failure of these vessels to dilate in response to neurogenic stimuli. These observations suggest that the difference in the magnitude of the dilator response in muscle and skin during activation of ventricular baroreceptors may result from greater withdrawal of sympathetic nerve traffic to skeletal muscle. This appears to occur also with activation of carotid sinus baroreceptors since carotid sinus nerve stimulation causes greater dilatation in muscle than skin (11). The peak vasodilator response occurred later in muscle than in paw. It is difficult to draw conclusions about the relative timing of the reflex response to outflow obstruction in the two beds from this observation since the magnitude of the response was less in paw than in muscle. The peak reflex vasoconstrictor response to carotid occlusion also occurred later in muscle than in paw in these studies, but this response was also greater in muscle.

It is difficult from these experiments to identify the threshold for the increases in left ventricular pressure which are required to produce reflex vasodilatation. Since the carotid sinuses were intact in most of these experiments, the change in vascular resistance during outflow obstruction represents the net effect of vasodilatation resulting from increases in left ventricular pressure and vasoconstriction resulting from decreases in systemic arterial pressure. Therefore, attempts to determine the magnitude of increases in left ventricular pressure which are required to cause reflex vasodilatation from this study would probably overestimate the threshold. Striking vasodilatation usually occurred only during increases in left ventricular pressure of more than $50 \mathrm{~mm} \mathrm{Hg}$, but definite vasodilatation was seen in four experiments with increases of left ventricular pressure of $15-40 \mathrm{~mm} \mathrm{Hg}$ despite a fall in arterial pressure which would be expected to produce reflex vasoconstriction.

In the preceding study, we demonstrated that forearm vasoconstrictor responses to leg exercise are in- hibited or reversed in patients with aortic stenosis (4) and suggested that this results from activation of ventricular baroreceptors. Since reflex forearm vasoconstriction during leg exercise occurs largely in skeletal muscle (12), the results of the present study are consistent with the suggestion that reflexes arising in ventricular baroreceptors could inhibit or reverse the constriction.

Baroreceptors in atria and pulmonary vessels participate in the regulation of vascular tone (13-14). Since left atrial pressure increased during left ventricular outflow obstruction, we had to evaluate the contribution of reflexes arising in atrial or pulmonary vascular baroreceptors. Inflation of a balloon at the mitral valve produced increases in left atrial pressure which were comparable to those resulting from outflow obstruction, but failed to produce vasodilatation. Decreases in arterial pressure, which promote reflex vasoconstriction by activating carotid sinus reflexes, were greater during outflow than inflow obstruction. The effect of this difference in arterial pressure response on comparisons of vascular responses to outflow and inflow obstruction was minimized by denervating the carotid sinuses before the interventions. In addition, it should be noted that even with intact carotid sinus reflexes, the greater decreases in arterial pressure during outflow obstruction would promote vasoconstriction and reduce, not augment, the vasodilator response. Therefore, the greater vasodilator responses during outflow obstruction cannot be explained by the changes in arterial pressure. The results of these experiments suggest that reflex vasodilatation during left ventricular outflow obstruction resulted from activation of left ventricular baroreceptors and not from low pressure baroreceptors in atria or pulmonary vessels. These results are consistent with the finding in the preceding study that forearm vasoconstrictor responses to leg exercise are inhibited in patients with aortic stenosis, but not in patients with mitral stenosis (4).

Responses to left ventricular distension cannot be attributed to myocardial ischemia since coronary artery occlusion produces reflex vasodilatation in paw and vasoconstriction in muscle (6) in contrast to slight dilatation in paw and pronounced dilatation in muscle in this study.

Aviado and Schmidt (1) demonstrated that reflex vasodilator responses to left ventricular stretch are mediated through vagal afferent and sympathetic efferent pathways. Reflex vasodilatation produced by stimulation of carotid sinus baroreceptors results from both withdrawal of adrenergic constrictor tone and activation of sympathetic dilator pathways (15-16). Our study suggests that reflex vasodilatation caused by activation of ventricular baroreceptors results from 
withdrawal of adrenergic constrictor tone. Phentolamine, which releases adrenergic tone by blocking alpha receptors, abolished the dilatation during outflow obstruction, but also resulted in a nonspecific reduction in dilator capacity by decreasing resting vascular resistance. Phentolamine decreased the ratio of dilator responses to outflow obstruction divided by responses to an internal dilator control, glyceryltrinitrate. In other words, blockade of dilator responses to outflow obstruction was greater than reduction in responses to a nonspecific dilator stimulus. This indicates that phentolamine produced specific blockade of dilator responses to outflow obstruction and supports the hypothesis that the dilatation results from withdrawal of adrenergic constrictor tone. Activation of sympathetic histaminergic and cholinergic pathways apparently did not contribute, because administration of tripelennamine and atropine did not decrease the dilatation.

\section{ACKNOWLEDGMENTS}

We gratefully acknowledge the secretarial assistance of Ms. Julianne Garvey and Ms. Donna Thomas.

The study was supported by Clinical Investigatorships from the Veterans Administration; by Research Grants HL 02644 HL 09835, and HL 14388 and Research Career Development Award HL-K4-28749 from the National Heart and Lung Institute; and by grants from the Iowa and American Heart Associations.

\section{REFERENCES}

1. Aviado, D. M., Jr., and C. S. Schmidt. 1959. Cardiovascular and respiratory reflexes from the left side of the heart. Am. J. Phy'siol. 196: 726.

2. Salisbury, P. F., C. E. Cross, and P. A. Rieben. 1960. Reflex effects of left ventricular distention. Circ. Res. 8: 530 .
3. Ross, J., Jr., C. J. Frahm, and E. Braunwald. 1961. The influence of intracardiac baroreceptors on venous return, systemic vascular volume, and peripheral resistance. J. Clin. Inc'est. 40: 563.

4. Mark, A. L., J. M. Kioschos, P. G. Schmid, D. D. Heistad, and F. M. Abboud. 1971. Vascular responses to exercise in aortic stenosis: Possible implication of ventricular baroreceptors. Clin. Res. 19: 644.

5. Calvelo, M. G., F. M. Abboud, D. R. Ballard, and W. Abdel-Sayed. 1970. Reflex vascular responses to stimulation of chemoreceptors with nicotine and cyanide. Circ. Res. $27: 259$.

6. Hanley, H. G., J. C. Costin, and N. S. Skinner, Jr. 1971. Differential reflex adjustments in cutaneous and muscle vascular beds during experimental coronary artery occlusion. Am. J. Cardiol. 27: 513.

7. Uvnäs, B. 1954. Sympathetic vasodilator outflow. Phy'siol. Rev. 34: 608 .

8. Beck, L. 1965. Histamine as a potential mediator of active reflex dilatation. Fed. Proc. 24: 1298.

9. Brody, M. J. 1966. Neurohomoral mediation of active reflex vasodilatation. Fed. Proc. 25: 1583.

10. Steel, R. G. D., and J. H. Torrie. 1960. Principles and Procedures of Statistics. McGraw-Hill Book Company, Inc., New York. 1st edition.

11. Abboud, F. M. 1972. Control of the various components of the peripheral vasculature. Fed. Proc. 31: 1226.

12. Bevegard, B. S., and J. T. Shepherd. 1967. Regulation of the circulation during exercise in man. Physiol. Rev. $47: 178$.

13. Paintal, A. S. 1953. A study of right and left atrial receptors. J. Physiol. 120: 596.

14. Coleridge, J. C. G., and C. Kidd. 1963. Reflex effects of stimulating baroreceptors in the pulmonary artery. $J$. Physiol. 166: 197.

15. Heitz, D. C., R. A. Shaffer, and M. J. Brody. 19;0. Active vasodilatation evoked by stimulation of sinus nerve in the conscious dog. Am. J. Physiol. 218: 1246.

16. Takeuchi, T., and J. W. Manning. 1971. Muscle cholinergic dilators in the sinus baroreceptor responses in cats. Circ. Res. 29 : 350. 